All letters must be typed with double spacing and signed by all authors.

No letter should be more than 400 words.

For letters on scientific subjects we normally reserve our correspondence columns for those relating to issues discussed recently (within six weeks) in the BMF.

We do not routinely acknowledge letters. Please send a stamped addressed envelope if you would like an acknowledgment.

- Because we receive many more letters than we can publish we may shorten those we do print, particularly when we receive several on the same subject.

\section{Deaths from haemolytic disease of the newborn in 1990}

SIR, - We recently analysed deaths from rhesus haemolytic disease in England and Wales in 1988 and 1989 and showed that whereas before 1988 the decline in deaths due to $\mathrm{Rh}$ haemolytic disease had been gradual, in 1989 the death rate suddenly halved; we wondered whether this was a chance finding.' We now report the figures for 1990.

The table gives details for the three years 1988-90. The figures for 1990 are extremely similar to those for 1989 , suggesting that 1988 was not a hiccup. Probably a combination of factors has saved lives-namely, improved obstetric care, fewer omissions of anti-D prophylaxis, and, possibly, more anti-D immunoglobulin being given for specific bleeding events during preg-

Classification of deaths registered by Office of Population Censuses and Surveys as due to haemolytic disease of fetus or newborn

\begin{tabular}{lrrr}
\hline Category & 1988 & 1989 & 1990 \\
\hline & Deaths due to anti- $D^{\star}$ & & \\
la & 3 & 2 & \\
1b & 5 & 5 & 5 \\
2 & 6 & 2 & 3 \\
3 & 6 & 1 & 2 \\
4 & 0 & 0 & 1 \\
\hline Total & 20 & 10 & 11 \\
\hline
\end{tabular}

\begin{tabular}{llll}
\hline Deaths $/ 100000$ live births & 2.9 & 1.5 & 1.6
\end{tabular}

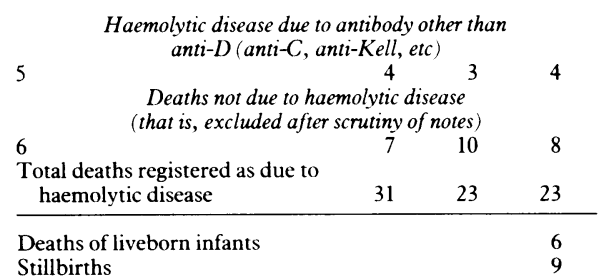

${ }^{\star}$ Category 1: mother believed to have been immunised by pregnancy after which she was not given injection of anti-Rh immunoglobulin (category la: immunising pregnancy occurred before 1970 (when anti-Rh immunoglobulin not widely available); category $1 \mathrm{~b}$ : immunising pregnancy occurred from 1970 onwards). Category 2: mother immunised during first pregnancy (anti-D detected during or within seven days after first pregnancy). Category 3: mother immunised despite having been given anti-Rh immunoglobulin after one or more previous pregnancies (failure of prophylaxis). Category 4: mother immunised by blood transfusion.

nancy. Interestingly, in 1990 a third of all the deaths from haemolytic disease of the newborn were due to antibodies other than anti-D (three anti-Kell and one anti-C) compared with $4 \%$ in 1977 , supporting the value of prophylactic anti-D immunoglobulin.

Investigations are still proceeding as to why new immunisations due to $\mathrm{D}$ antigen have remained stationary (G J Dovey, personal communication) since the decline levelled out in about 1985 .

Department of Public Health

RUTH HUSSEY

University of Liverpool,

PO Box 147,

Liverpool L69 3BX

Department of Geriatrics and Microbiology,

CYRIL CLARKE

University of Liverpool

1 Hussey RM, Clarke CA. Deaths from Rh haemolytic disease in England and Wales in 1988 and 1989. BMF 1991;303:445-6. (24 August.)

\section{Epidemic of bronchiolitis in infants}

SIR,-Our recent experience suggests that the epidemic of bronchiolitis due to respiratory syncytial virus in infants this winter has been more extensive and severe than usual. This clinical impression is supported by data from the Communicable Diseases Centre, whose four weekly returns of infections with respiratory syncytial virus (of which $88 \%$ were in children under 1 year old) show a pronounced increase for the four weeks ending 31 December 1991 over the same period in 1989 and $1990 .{ }^{1}$ We have also had a greater number of severe cases requiring intermittent positive pressure ventilation and would be interested to know if comparable units have had similar experiences.

In the past three months the paediatric department at this district general hospital has needed to ventilate 10 babies aged between 1 week and 3 months admitted with viral bronchiolitis. Of these, six had been born prematurely at 25-36 weeks' gestation, two had been born at term and had congenital heart disorders, and two were previously healthy babies who had been born at or near term. Eight of the infants were confirmed as being positive for respiratory syncytial virus.

Nine infants survived after intensive supportive treatment, including intermittent positive pressure ventilation. One infant born at 30 weeks' gestation and suffering from severe hyaline membrane disease died aged 11 weeks despite the use of tribavirin. All but one of the infants received intermittent positive pressure ventilation in the high dependency area of a general children's ward, thus throwing a considerable extra workload on nursing and medical staff.

With the increasing numbers of vulnerable babies, in particular those born prematurely and infants suffering from congenital heart disorders, this pattern of severe bronchiolitis seems likely to be repeated in subsequent winters. ${ }^{2}$ This has considerable implications for the provision of appropriate intensive care accommodation and adequate medical and nursing staffing for these patients, which will need to be considered by those concerned with planning paediatric services. ${ }^{34}$

TRACEY GIBBS J R HARPER

Northampton General Hospital,

Northampton NN15BD

1 Communicable Disease Report 1991;1:228.

2 Lebel MH, Gauthier M, Lacroix J, Rousseau E, Buithieu M. Respiratory failure and mechanical ventilation in severe bronchiolitis. Arch Dis Child 1989;64:1431-7.

3 Priftis K, Everard M, Milner AD. Outcome of severe acute bronchiolitis needing mechanical ventilation. Lancet 1990;335: 607

4 Mulholland EK, Olinsky A, Shann FA. Clinical findings and severity of acute bronchiolitis. Lancet 1990;335:1259-61.

\section{Prison medicine}

SIR,-Richard Smith's editorial makes a powerful case for major reorganisation of the prison medica service to bring it more closely into line with the reformed NHS.' A recent consultation document produced jointly by the Home Office and the Department of Health considered issues of con tracting and medical management in some detail. The report recommended that a reorganised, renamed prison health service should become a purchaser, commissioning a full range of health care services from the NHS and other providers. Smith argues that this does not go far enough and asks, "Why should the purchasing not also be done by the NHS?"

District health authorities will be well ahead of the prison health service in developing purchasing. They have input from public health departments, which are making rapid progress in health needs assessment and evaluating health care delivery. Public health skills are a vital component of NHS purchasing; it is difficult to envisage how prison health services would develop purchasing plans and contract specifications without this skill.

Responding to the consultation document, the regional directors of public health have welcomed these proposals for greater integration of the NHS and health care in prisons. They believe that this will lead to better services for prisoners and improved training and support for prison health staff. As well as recognising potential benefits at provider level we support Smith in advocating the involvement of district health authorities and family health services authorities as purchasers. Regarding prison populations as resident within their host health authority leads to these authorities having clear responsibilities under the NHS reforms to assess health needs and commission the best package of health services to meet those needs

The complexity of these changes must not be underestimated. Integration at provider level will require adequate resourcing in terms of money, 
staff training, and an adequate physical environment and is likely to encounter organisational and logistic problems initially. At purchaser level the organisation of funding will need to be considered, along with what further resources will be necessary for assessing and meeting the needs of some of the most vulnerable and disadvantaged members of our society.

The regional directors of public health welcome Smith's contribution to the debate and recognise the magnitude of changes being proposed. We recommend that several pilot schemes should be set up to evaluate further integration of prison health care into the NHS, which may include purchasing as well as provision of services.

MALCOLM FORSYTHE

Chairman,

Regional Directors of Public Health Group

South East Thames Regional Health Authority,

Bexhill on Sea

East Sussex TN39 3NQ

Smith R. Prison medicine: beginning again. BMf 1992;304 134-5. (18 January.)

2 Directorate of Prison Medical Services. Contracting for prison medical services: a consultation paper. London: Home Office. 1991.

SIR, - I was, to say the least, distressed by references to "British prisoners" and "people in custody in the United Kingdom" in Richard Smith's edicorial on prison medicine ${ }^{1}$ and I A MacFarlane and colleagues' article on diabetes in prison. ${ }^{2}$ I believe that both articles are referring to the prison service of England and Wales, which is of course quite separate from the prison services of Northern Ireland and of Scotland. This is particularly important in the context of Smith's remarks about mental hospitals and their relation to prisons, which would be misleading if taken to apply to the Scottish prison service.

My own prison has been served, on contract, by he partners of one general practice for over 25 years. This practice has been instrumental in medically supporting our non-segregation policy for prisoners seropositive for HIV to the same standard as the one it applies to members of the public who attend the practice in the community. Interestingly, these general practitioners, working with Saughton's newly appointed and first full time medical officer, have been developing a specia diabetic clinic within the prison, which is responding to changes in practice in the management of diabetes in the community.

In MacFarlane and colleagues' paper the statement that there are " 47000 prisoners in the United Kingdom" is incorrect. This excludes the prison populations of Scotland and Northern Ireland. Finally, may I also point out that prisoners in Scotland cannot be remanded for "many months," with all the medical problems that they may create. A person remanded in prison for trial cannot be held in custody for more than 110 days, whether the trial is complete or not; and that, as might be expected, is a considerable advantage for this prison.

J PEARCE

Governor,

Saughton,

Edinburgh EHI1 3LN

1 Smith R. Prison medicine: beginning again. BMJ 1992;304:134
5. (18 January.)
2 MacFarlane IA, Gill GV, Masson E, Tucker NH. Diabetes in
prison: can good diabetic care be achieved? BMf 1992;304

152-5. (18 January.)

SIR,-Richard Smith's editorial discusses the prison medical service.' The fact is that two thirds of the medical care in prisons is given by loca general practitioners. By what strange metamorphosis do these doctors manage to practise on standard of medicine in their surgeries and then a different standard in the prison down the road thus causing the chief inspector of prisons to say that the standard of medical care afforded to prisoners falls far short of that provided in the community?

Smith says that the Home Office is making heavy weather of what is known as the scrutiny report. This report suggests that the senior medical officer in the prison should buy in all the services required from the local NHS and, in particular, the psychiatric services. The Home Office can hardly be blamed for wishing to wash its hands of providing medical services to patients who often have little to do and live in "dirty, cramped, and dispiriting conditions" and of whom it has been reported that $37 \%$ have a psychiatric disorder $(2 \%$ of these have psychosis)

The senior medical officer will hire a psychiatric team to provide a 24 hour service, in particular to deal with remand prisoners. Much of the work with remand prisoners is the wheeling and dealing of obtaining beds in local psychiatric hospitals. Requests for these beds often meet with reluctance or the reply that there is a waiting list. It is hardly surprising that psychiatrists are not queuing up to do this demanding work, even if there was the possibility of there being enough of them to do it. A good prison medical officer is a permanent feature who plays an important part in maintaining morale in the prison hospital. Some of us who visit prison regularly live in fear that one day the prison medical service will collapse and there will be a dangerous hiatus. It is time that prison medica officers stopped being employed by the Home Office and were employed by the Special Hospital Services Authority, which runs the special hospital and has much knowledge of mentally abnorma offenders.

Fromeside Clinic,

Bristol BS16 1ED

1 Smith R. Prison medicine: beginning again. BMf 1992;304 134-5. (18 January )

Gunn J, Maden A Swinton M. Treatment needs of prisoners with psychiatric disorders. BMF 1991;303:338-41.

SIR, - The College of Prison Medicine is concerned with standards of health care and with training. It members are dedicated to the specialty of prison medicine. The college welcomes the scrutiny report for bringing to the public's attention deficiencies in the service that have long been apparent to those in it.' But though we welcome the possibility of change for the better, we entertain serious doubts about the validity of some conclusions and the feasibility of others.

Over half of the doctors in the prison medica service are members of one or other of the royal colleges. All will welcome the appointment of Sir Donald Acheson as first chairman of the prison service's health advisory committee. Few could do other than welcome a wider role under condition akin to those in the NHS - perhaps a special health authority incorporating the prison medical service forensic psychiatry, consultants working in specia hospitals, and forensic medical practitioner (police surgeons). But there are far more contentious recommendations - for example, the sug gestions that the prison medical service should shrink to a smaller body of purchasers buying in from a large body of provider general practitioners that a far greater (even total) distinction should be made between clinical practice and medica management, and that the recruitment of even ful time prison medical officers ("prison clinicians") should be achieved by offering contracts

The purchaser-provider concept will lead to fragmentation of care, management, and responsibility. The cost of employing such a workforce of general practitioners is likely to be prohibitive. Part time general practitioners mus always prioritise their time in favour of their main commitment - their NHS patients - and cannot be expected to sustain the detailed knowledge of the whole prison and its inmates that enables the prison doctor to work with the governor to run a safe and happy prison. The managerial and clinica roles of the prison doctor cannot be clearly differentiated. And the concept of limited contracts as applied to full time prison doctors will be a considerable disincentive to most of those who, already well qualified and experienced in medicine, have good reason when considering work of such a demanding nature to expect permanent superannuable employ.

The scrutiny has cast its shadow over the future of those of us who work in this service, but we are determined to maintain morale and continue to deliver good medical care.

College of Prison Medicine,

R C ILBERT

PO Box 60, Wakefield

West Yorkshire WF2 9YZ

1 Smith R. Prison medicine: beginning again. BMf 1992;304: 134-5. (18 January.)

\section{Antidiarrhoeal drugs for acute diarrhoea in children}

SIR,--In their review of antidiarrhoeal drugs in diarrhoea Anthony $M$ de $\mathrm{L}$ Costello and Tariq Iqbal Bhutta conclude the "More objective information on the rational use of drugs is needed in all countries, ... and consumers need to have direct access to it."

Dialogue on Diarrhoea is an international quarterly newsletter that has been published continuously since 1980; a version in English is available free to readers in developing countries from Appropriate Health Resources and Technologies Action Group, 1 London Bridge Street, London SE1 9SG, United Kingdom. For the past 15 months the newsletter has been running a series on drugs in childhood diarrhoea. This series is partly based on the World Health Organisation's programmes for rational use of drugs and controlling diarrhoeal diseases. ${ }^{2}$ The series has considered not only antidiarrhoeal drugs and antibiotics but also the behaviour of doctors in prescribing drugs, methods of promoting better prescribing practices, reviews of publications about medicine and prescribing, and reports on programmes promoting appropriate drug use in different countries. This is a major educational effort as Dialogue on Diarrhoea has a circulation of over 170000 copies in English and over 100000 in other languages, including Spanish, French, Portuguese, Chinese, Tamil, Bangla, and Nepali.

The perceptions and demands of the public, as well as prescribing practices, are important in determining the types of treatment that are acceptable. The largest review of mothers' beliefs about, and practices in, diarrhoeal disease and its management was conducted in India for Unicef by the Indian Marketing Research Bureau. ${ }^{3+}$ Almost 10000 mothers with children under 5 were scientifically selected from 34 sociocultural regions and were interviewed. In $65 \%$ of all diarrhoeal episodes the mothers consulted health professionals, and over $80 \%$ of these professionals were "private practitioners." Although $60 \%$ of the "doctors" knew about oral rehydration therapy, the first response of $80 \%$ was to give medicine or injections. Drug treatment not only delays ora rehydration therapy but can displace it from the treatment routine. In India the mother and families expected to pay for medicine and were willing to do so. The average cost of treatment per episode was 45 rupees ( $£ 1.75$ at that time) when the monthly expenditure per person was 213 rupees $(£ 8 \cdot 19)$.

The task of informing and educating is one thing. Changing perceptions, expectations, and prescribing habits is another and will require sustained programme over many years. This is a worthwhile effort because of the high incidence of 